\title{
Research on the Coupling Relationship Between Poetry and Legends Based on Statistical Regularity and Cluster Analysis
}

\author{
Wen Tang \\ Linyi University, 276000, Linyi, China \\ e-mail: wentang_wt@126.com
}

Keywords: Statistical regularity; coupling relationship; clustering analysis

\begin{abstract}
The myths and legends are original human ideology, their understanding and interpretation of the world, and their encyclopedic knowledge system. As the beginning of China's fantasy, the human literature source, the traditional culture of the important composition part of the ancient myths and legends, regardless of ideological content or artistic style produce important influence on all the later writers, as later writers' creation of outstanding literary works of the material, the later culture the development also had a profound impact. In this paper, the old "the son of bear legend and epic" Beowulf "story is used as an example to study the coupling between poetry and legends. And then we use cluster analysis methods to study the literary works of aesthetic value. It can be seen from the relationship between poetry and legends of literary works the myths and legends prototype, but the binding characteristics of the age and geographical features are beyond the myths and legends prototype.
\end{abstract}

\section{Introduction}

Myths and legends are the original human ideology, their understanding and interpretation of the world, their encyclopedic knowledge systems, and also their expression of their wishes[1]. It seems very absurd in the modern description, with the beginning of China eyes of the world the origin of the universe model, soaring relations, national history, tutoring concepts as well as all kinds of daily life knowledge[2]. To a certain stage when the development of human civilization, the myth is more or less from the original state, especially to get rid of it to explain the universe, the natural functions, and more and more to reflect the emotional life of human society, conflict, which become a real the myth of literature[3]. "This works like ancient Greece, Homer and the many tragedies: the myth of literature distinguishing feature is the "God" has a rich humanity. Fairy tales, and myths materials are often used by descendant writers, creating new works with specific color. "Legend" and "myth" in concept can sometimes be interoperable, but "legend" is often associated with a specific time, place related. Myths and legends, this presence is quite a long time, still has a tremendous impact on the cultural phenomenon, its emergence and continuation by no means accidental[4]. It embodies the spirit of a nation "living fossil", is the resultant of history, load generation and continuation of that society, a lot of information. Myths and legends reflect not only these, but also reflect a nation's cultural psychological form. The same myths and legends are in different literary works of different periods of use, reflecting the creation of their purpose[5]. Ancient myths and legends as the beginning of China's fantasy can often inspire the imagination of future generations of writers to become the material of the outstanding literary works in their creations, and thus cause a considerable impact on the development of literature. Myths and legends' impact on later culture can not be underestimated.

\section{Coupling analysis of literary works}

\section{Research objects and methods}

We used questionnaire method to study as a literary epics and legends of reading effect, first we design the questionnaire form, including its literary theme, comprehensibility, the far-reaching significance, through questionnaire investigation statistic data that we are shown in Table 1. 
Table 1. Structure comparison of literary

\begin{tabular}{|l|l|l|l|}
\hline & $\begin{array}{l}\text { literary themes } \\
(\%)\end{array}$ & intelligibility (\%) & $\begin{array}{l}\text { Significance } \\
(\%)\end{array}$ \\
\hline Beowulf & 53 & 44 & 63 \\
\hline The son of the bear & 47 & 56 & 37 \\
\hline
\end{tabular}

As shown in Table 4, in " Beowulf " and "bear his " research analysis can be seen in the two themes in the literature analysis index reaching 50\%; intelligibility index also tends to 50\%, the two meaning is far-reaching index is also a great degree of similarity, over $30 \%$. The cylindrical visual diagram as shown in figure 1.

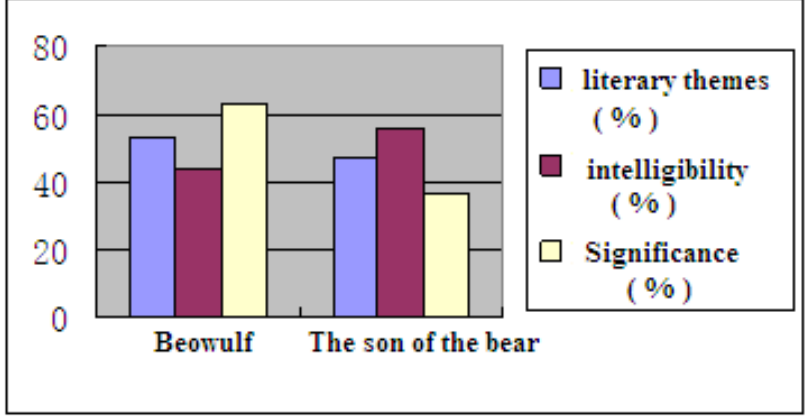

Fig. 1. Visual diagrams of structural literature

\section{Research and analysis}

The research and analysis are shown in Table 2.

Table 2. Research and analysis and ideas

\begin{tabular}{|l|l|l|}
\hline Research and analysis & Method & Process \\
\hline Model establishment & $\begin{array}{l}\text { Use model analysis techniques and } \\
\text { cluster analysis algorithm }\end{array}$ & $\begin{array}{l}\text { First of all the object is followed } \\
\text { by the establishment of the } \\
\text { literature information function }\end{array}$ \\
\hline Coupling analysis & Use coupling analysis techniques & $\begin{array}{l}\text { Correspondence, intertextuality, } \\
\text { and heroism }\end{array}$ \\
\hline
\end{tabular}

\section{Model establishment}

This paper uses the model to construct the coupling model, the literary works of the model uses the method of cluster analysis is necessary. The cluster analysis algorithm design to literary works in the Internet IT share some time on the degree of time, space, degree and capital dimensions[6]. Therefore, the implementation of cluster analysis for all objects, and the idea of cluster analysis are as follows:

All objects are $\mathrm{X}=\left\{x_{1}, x_{2}, x_{3}, x_{4} \cdots x_{n}\right\}$, in which $x_{i}, i=1,2,3 \cdots n$ is model vector, and its cluster analysis idea is to find a $P=\left\{P_{1}, P_{2}, P_{3} \cdots P_{n}\right\}$, in $\mathrm{X}$ to meet $\mathrm{X}=\bigcup_{i=1}^{k} P_{i}$, in which $P=\left\{P_{1}, P_{2}, P_{3} \cdots P_{n}\right\}$, and $P_{i} \neq X$ error equal is $I_{i}=\sum_{i=1}^{K} \sum_{K=P_{j}}\left(d_{i_{j}}\right)^{2}$ and in which $d_{i j}=\left\|x_{i}-z_{i}\right\|_{[7] \text {. }}$

The information space function of the literary works is as follows:

$$
\begin{aligned}
& S^{t+1}=\left\{\overline{S_{1}{ }^{t}}, \overline{S_{2}{ }^{t}} \cdots, \overline{S_{\text {best }}{ }^{t}}, \overline{S_{i+1}{ }^{t}}, \overline{S_{m}{ }^{t}}\right\}, f\left(\overline{x^{t}{ }^{b e s t}}\right)>f\left(\overline{s^{t}{ }_{m}}\right)
\end{aligned}
$$

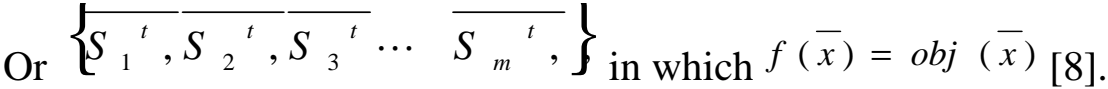

\section{Coupling analysis}

After the Vikings settled in England peninsula, their literary works were also transmitted to the United Kingdom, which include the manuscript of "Beowulf". Through the centuries, from the Scandinavian ancient to the hands of England, Anglo-Saxon manuscript of "Beowulf" and its owners, the poetry has been constantly modified already a far cry from the original[9]. As scholars Jihui said, "We read poetry very likely repeated additions and deletions of several generations, patchwork, purification, and even a fully updated version." (Li Fu Ning 2004:95) However, despite the "Beowulf 
"presentation after several generations of changes, which hosted the" the son of the bear of the embryonic form of the legend is always looming. Intertextuality between the elegant "Beowulf" and "The son of the bear legendary from three aspects: First, hero in the poetry Beowulf and the mighty legend" Bear Son "between the corresponding relations; Second, the poetry of the story, especially the clips and detailed description of the many stories and legends have a strong intertextuality[10]; Third, the poem "Beowulf," continues the legend of the "the son of the bear of the praise style of heroism, which is shown in Figure 2.

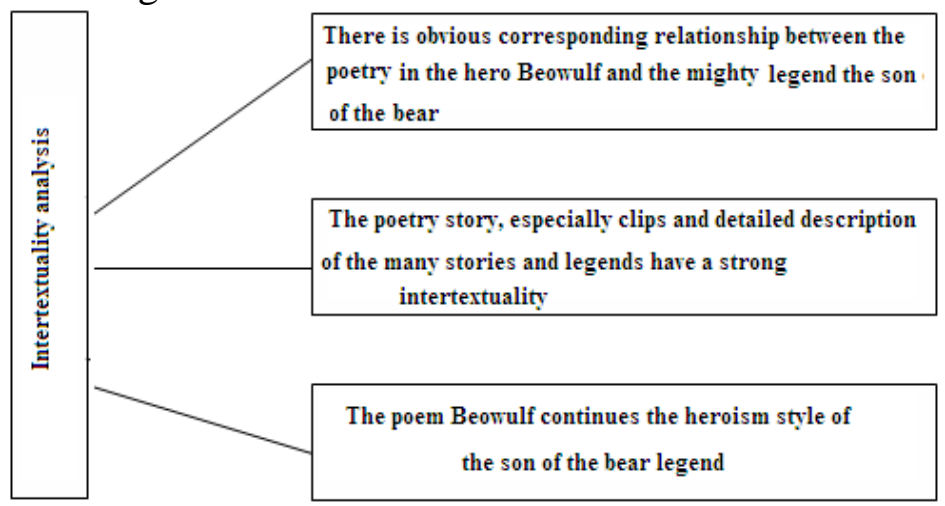

Fig. 2. Intertextuality analysis

There is obvious corresponding relationship between the poetry in the hero Beowulf and the mighty legend the son of the bear

Beowulf has the refraction of the son of the bear shadow. As the name suggests, the "the son of the bear of the protagonist of the story is the descendants of the bear, he inherited the bear blood and mighty. To correspond with the name of a hero "Beowulf" implied "Bear" means. The Old English word Beowulf means "hunter" in the specific context of the "hunter" points to a beast - "Bear". The mouth of poetry with the Luo Sejia described Beowulf: "A pair of black street, ten fingers, no less than / 30 the power of individuals" (379-380). Beowulf is the most important weapon is his "black street" dual "black street" effort comparable to the 30 soldiers the sum of the forces. He has to play "Bear force, armed with nothing but an arm of the avaricious generation of students tear off. Can see from the correspondence between Beowulf and the Bear ", the legend of the great poetry of.

The poetry story, especially clips and detailed description of the many stories and legends have a strong intertextuality

There are several important motif in the "The son of the bearlegend, like" the son of the bear and partner came to the fertile land, "magic sword", "the son of the bear of depth monster lair, rescue Princess", etc. these motif are able to reproduce the "Beowulf" mostly. And bear the child, for example, found along the footprint of the monster lair alone jumped into the plot of which echoes Beowulf is also along the forest trail one set of footprints "(1402-1403) came to the pit, and alone into it before to the lair of the Dage avaricious generation of the mother. To kill the avaricious on behalf of the mother and the Fire Dragon, Beowulf raised his magic sword. After three fight, "Beowulf" poet presented to the treasures of the audience will appear in the "the son of the bear of the legendary monster. Seems to have realized the lack of women's roles in the legend, the singer of the poet to arrange Luo Sejia after Ge avaricious generation fragment about the Danish public Seoul White, Chairman of the sadness[11]. If, as John Wei Kele said, the poem "Beowulf" and "facts" and "fiction" is interacting with each other, difficult to distinguish (2009:59), this fragment of the then the Schill white sorrow "clearly to make up for the poetry in the "rescue the princess" motif.

\section{The poem Beowulf continues the heroism style of the son of the bear legend}

Beowulf and the monster's fighting story fits the fundamental praised the heroism of the the son of the bear legend. This ancient legend reaction Norse society uncivilized era of human's fear, the fear of natural forces and wants to conquer the natural desire. Time the eyes, the mysterious nature turned into a tyrannical nature of the monster, and the son of the bear of the legendary hero, has infinite power, and sometimes have been given the speed of a lion, wings of an eagle, the ant's body, people the desire for these supernatural ability to cope with the vagaries of nature. At the same time, in the 
Nordic ancient ancient Germanic society, the highly respected Ares Odin - Warden of the worship of war[12]. This has also become one of the reasons for the prevalence of heroism. As Eliade, religious sociologist, said: "In traditional society, especially the ancient Germanic society, the war is a ritual to prove its rationality in theology." (2005:574) highlight the heroism of this, "Beowulf" has inherited the concept of the son of the bear legend.

\section{Reflection beyond the relationship}

"Beowulf" did not stop at the imitation of the the son of the bear legend and heritage. On the contrary, it combines the historical background and religious ideas of the English local continuous improvement, beyond the legend of the fixed mode and has a new meaning and significance. It is because of the connotation and extension of the "the son of the bear of legend beyond," Beowulf "has a new era, regional, and literature, and become an important springboard for one of the critics to understand the society and culture of the Middle Ages. Relative to the fixed mode and content of the "the son of the bear of legend" Beowulf "mainly has three changes: First, poetry celebrate the legend of medieval Scandinavia, Scandinavian heroism at the same time, gently pointed out that heroism lonely era; Second, poetry on the basis of the "the son of the bear of legendary pagan ideology, adding more Christian thought, which highlights the Region and Time; Third, implicit in times the impact on the heroism of the Middle Ages, as well as the integration of regional exotic customs, "Beowulf" has the elegy atmosphere that not exist the son of the bear of the legendary", which is shown in Figure 3.

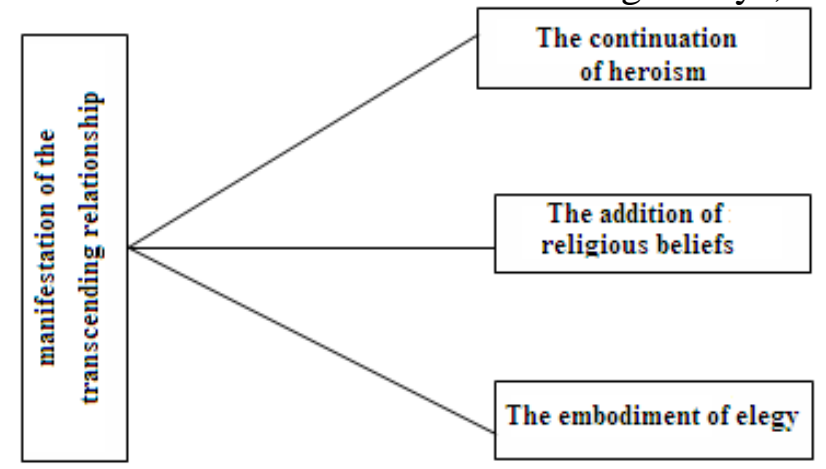

Fig. 3. Manifestation of the transcending relationship

(1) First of all, the legend of the the son of the bear of the celebrated heroism in the epic" Beowulf "the continuity, but the poet that the heroism of the Middle Ages Fashion is going downhill. Embodied the flaunt courage, responsibility, loyalty and belief in the medieval heroism indeed be in Beowulf who he beat the Ge avaricious behalf of the mother and child and kill the fire dragon. However, according to some critics, Beowulf is not a completely idealized typical Anglo-Saxon king, he and the other kings of the poem, which is full of profound contradictions. "(Jihui 2003:57)[13].

"The son of the bear legend in the plot is a hero to saving the United States: Bear's son defeated the monster and rescue the princess (girl). "Beowulf" poet, although the wording has been added "the Schill white sorrow" this fragment, but the role of women in poetry is still very few. In the poem, the only women obtaining the floor may be Queen Osevi in Europe. As can be seen from the description of the poet, this is a very arrogant queen, and her noble, elegant, calm and decent. Beowulf fight in the Ge avaricious on behalf of the practice meeting, with Europe color toast and hero blood surging.

(2) Second, for the son of the bear legend, the background story of" Beowulf "is a pagan ideology dominated by the ancient Scandinavian society, different groups over the centuries to rewrite. It now appears that the epic story framework basically is built in the Christian ideologically. Peninsula spread of Christianity in England began in BC 55 years of Julius Caesar, Roman conquest, until the 7th century Anglo-Saxon nation was only thoroughly Christian. They brought from the home of the Nordic religion as "pagan" (paganism), while Christianity has become a veritable "Orthodox." Religious unity undermined the fundamental differences among ethnic groups in the peninsula of England, becoming one of the England national consciousness originator point. Admittedly, pagan ideology plays an important role in the story of "Beowulf", for example, the epic to the cremation of the Danish king Hilde, to the end of the High King Tut for the cremation of Beowulf, this urn burial 
culture It is pagan thought one of the important manifestations (Eliade 556). With the development of the epic of the times and regional to be updated, Christian thought and paganism co-exist, and gradually to occupy a dominant position. For example, when about to Ge the avaricious behalf of the rampant deer Hall, the poet mentioned the Luo Sejia and minister in desperation resort to pagan idols, and that this is the "Vulgar" heart hidden in hell "infidel fantasy, and then he wrote: "Happiness belongs to / and that after the death of my Lord ascended to heaven to find / go to the Father arms seeking the man of peace" (186-188). In "Beowulf" many details reflect the intertextuality with the Old Testament of the Bible.

(3) Finally, the elegiac qualities "Beowulf" has the elegy characteristics that the son of the bear legend doesn't have. Some legend versions bear the son finally die from the hands of the monster, but contains no dirge means that, at this point the epic "Beowulf" beyond the original version of the legend. Critics Tolkien said, if one word to describe the "Beowulf" and "We can only choose the 'Elegy"', because "Beowulf" is a hero - the dirge epic (heroic-elegiac poem individual) (1958:33) is generally believed that the poem Beowulf fight object anchored can be divided into three parts. The first two parts of the story, Beowulf is as young adults, a fight with the flames, he has to age. So, to the time of the split point, the poem can be divided into two parts. From maturity to old age, from the prime of life to frail older, from victory to defeat and death, the whole poem is a hundred years of life, short-lived praise and mourning. As Jihui said, "dichotomy” in fact deepens the theme of this epic (Li Fu Ning 2004:96).

\section{Conclusion}

Poetry and legends belong to the same type of art. They range from the oral form to the pen above records, carrying the historic mission, but in the form of literature. Although illusory and exaggerated, but the phenomenon would have a problem exaggeration of the real performance reflects the reality, in the spreading process. At the same time, because of the historical origins, this make between their bound inextricably linked. But poetry and legend still have their own unique responses to the value of them at different meanings. The old "the son of the bear" legend and epic" Beowulf "story is used as an example to study the aesthetic value of literary works. It can be seen from the relationship between the two that the creation of literary works and poetry and legends are inseparable.

\section{References}

[1] Xu GuangYao. The analysis on the monopoly agreement terms of Anti-monopoly law[J]. Journal of law, 2009 (1) : 18-20

[2] LuJiong xing, HouFan. The anti-monopoly suitable exception system research, in swim advised honor (editor) : Comparative study on anti-monopoly law [A]. The people's court press, 2011(1) : 202

[3] Mei GuangHui.Micro agent on the principle of anti-monopoly exception system [J]. Journal of the administrative cadre institute of politics and law in Heilongjiang province, 2012(1):33-35

[4] Zheng PengCheng. Analysis on the development trend of American anti-monopoly law exception system[J]. Modern science, 2009(1):67-69

[5] Xu ShiYing. The new development of the eu competition law and their inspiration to China [J]. Journal of law, 2010(8):132-134.

[6] Ma Jun. The necessity of theory in Chinese exception anti-monopoly law system [J]. Seeking truth from facts, 2009 (6) : 62-64

[7] Shi Jichuan. Utilities introducing competition mechanism and the "anti-monopoly" [J]. Morden Law, 2010(6):47-53.

[8] Han YongGong. The European Union competition exempt system and their inspiration to China [J].E conomy, 2009, 18 (1):101-104. 
[9] Lin YanPing. The anti-monopoly law suitable exception system [J]. Journal of law, 2011(3):22

[10] Dong Suzhan. Theory for anti-monopoly law exempt system [J]. Journal of Nanjing university (social sciences), 2009(4):55-56.

[11] Li Hui, ChengJianhua. Analysis on some problems of the anti-monopoly legislation [J]. Journal of Sui Hua college, 2011 (12) : 64-65

[12] Sun Jin. The reasonable definition of the anti-monopoly law system construction and suitable exception policy monopoly [J]. Law review (bimonthly), 2010 (3) :54-56

[13] Zhu E. China's anti-monopoly exception system [J]. Economy, 2009 (9) : 277-278 